\title{
The Molecular Mechanisms of Action of Photobiomodulation Against Neurodegenerative Diseases: A Systematic Review
}

\author{
Mayukha Bathini ${ }^{1,2}$ D $\cdot$ Chandavalli Ramappa Raghushaker ${ }^{2}$ D Krishna Kishore Mahato $^{2}$ (D)
}

Received: 1 August 2020 / Accepted: 18 November 2020 / Published online: 10 December 2020

(c) The Author(s) 2020

\begin{abstract}
Neurodegenerative diseases might be slow but relentless, as we continue to fail in treating or delaying their progression. Given the complexity in the pathogenesis of these diseases, a broad-acting approach like photobiomodulation can prove promising. Photobiomodulation (PBM) uses red and infrared light for therapeutic benefits, working by stimulating growth and proliferation. The implications of photobiomodulation have been studied in several neurodegenerative disease models. It has been shown to improve cell survival, decrease apoptosis, alleviate oxidative stress, suppress inflammation, and rescue mitochondrial function. In in vivo models, it has reportedly preserved motor and cognitive skills. Beyond mitochondrial stimulation, the molecular mechanisms by which photobiomodulation protects against neurodegeneration have not been very well studied. This review has systematically been undertaken to study the effects of photobiomodulation at a molecular level and identify the different biochemical pathways and molecular changes in the process. The data showed the involvement of pathways like extracellular signal-regulated kinase (ERK), mitogen-activated protein kinase (MAPK), and protein kinase B (Akt). In addition, the expression of several genes and proteins playing different roles in the disease mechanisms was found to be influenced by PBM, such as neurotrophic factors and secretases. Studying the literature indicated that PBM can be translated to a potential therapeutic tool, acting through a spectrum of mechanisms that work together to decelerate disease progression in the organism, which is difficult to achieve through pharmacological interventions.
\end{abstract}

Keywords Neurodegenerative diseases $\cdot$ Photobiomodulation $\cdot$ Molecular pathway $\cdot$ Neuroprotection

\begin{tabular}{|c|c|c|c|}
\hline \multicolumn{2}{|c|}{ Abbreviations } & $\mathrm{IP}_{3}$ & Inositol triphosphate \\
\hline \multirow{2}{*}{$\begin{array}{l}\text { ABCB } 1 \\
\text { p-Akt }\end{array}$} & ATP-binding cassette subfamily B member 1 & $\mathrm{IP}_{3} \mathrm{R}$ & Inositol triphosphate receptor \\
\hline & (phosphorylated) protein kinase B & JAK & Janus kinase \\
\hline APPswe & Swedish mutation of APP & JNK & c-Jun N-terminal kinase \\
\hline ATP & Adenosine triphosphate & mTOR & Mammalian target of rapamycin \\
\hline \multirow{2}{*}{$\begin{array}{l}\mathrm{Bcl} 2 \\
\mathrm{Bcl}-\mathrm{xL}\end{array}$} & B cell lymphoma 2 & NADPH & Nicotinamide adenine dinucleotide \\
\hline & B cell lymphoma-extra large & & phosphate \\
\hline \multirow{2}{*}{$\begin{array}{l}\text { CD45 } \\
\text { (p-)cPLA2 }\end{array}$} & Leukocyte common antigen & NRF2 & Nuclear factor erythroid 2-related factor \\
\hline & $\begin{array}{l}\text { (phosphorylated) Cytoplasmic phospholipase } \\
2\end{array}$ & PGC-1 $1 \alpha$ & $\begin{array}{l}\text { Peroxisome proliferator-activated receptor- } \\
\text { gamma coactivator } 1 \text { alpha }\end{array}$ \\
\hline CREB & cAMP response element-binding protein & PI3K & Phosphoinositide 3-kinase \\
\hline DAG & Diacylglycerol & PKC & Protein kinase $\mathrm{C}$ \\
\hline GSK3 $\beta$ & Glycogen synthase kinase 3 beta & Raf & Rapidly accelerated fibrosarcoma protein \\
\hline \multirow{2}{*}{\multicolumn{2}{|c|}{$\begin{array}{l}\text { Krishna Kishore Mahato } \\
\text { kkmahato@gmail.com }\end{array}$}} & $\mathrm{AT}$ & $\begin{array}{l}\text { Signal transducer and activator of } \\
\text { transcription }\end{array}$ \\
\hline & & Syk & Spleen tyrosine kinase \\
\hline \multirow{2}{*}{\multicolumn{2}{|c|}{$\begin{array}{l}\text { Manipal School of Life Sciences, Manipal Academy } \\
\text { of Higher Education, Manipal, Karnataka 576104, India }\end{array}$}} & TASTPM & TAS10 x TPM double transgenic \\
\hline & & TGF- $\beta$ & Transforming growth factor beta \\
\hline \multirow{2}{*}{\multicolumn{2}{|c|}{$\begin{array}{l}\text { Department of Biophysics, Manipal School of Life } \\
\text { Sciences, Manipal Academy of Higher Education, Manipal, } \\
\text { Karnataka 576104, India }\end{array}$}} & TNF- $\alpha$ & Tumor necrosis factor alpha \\
\hline & & Wnt & integration site \\
\hline
\end{tabular}




\section{Introduction}

Neurodegenerative diseases like Alzheimer's disease, Parkinson's disease, and Huntington's disease are characterized by the progressive structural or functional loss and death of neurons, eventually leading to a decline in cognitive, memory, and motor abilities. The pathogenesis of these diseases involves multiple overlapping aspects that are common among many neurodegenerative diseases, one of them, including protein aggregates. In Alzheimer's, secretases generate amyloidogenic peptides (A $\beta 40$ and $\mathrm{A} \beta 42$ are the most common isoforms) from the amyloid precursor protein (APP), which can misfold, aggregate to form extracellular amyloid plaques (Sanabria-Castro et al. 2017; Chen and Mobley 2019). And Parkinson's disease, known to occur as a loss of dopaminergic neurons in the substantia nigra pars compacta, is attributed to lewy body aggregation containing the amyloid protein $\alpha$-synuclein $(\alpha-$-syn) (Maiti et al. 2017). Polyglutamine (polyQ) diseases like Huntington's disease and spinocerebellar ataxia are caused by a trinucleotide repeat expansion in the genes or polyglutamine tract expansion in the proteins, leading to misfolding and altered functions (Estrada Sánchez et al. 2008). The protein aggregates can interact with several mitochondrial components like cytochrome c oxidase (CCO), membrane translocases, voltage-dependent anion channels, and $\mathrm{F}_{1} \alpha$, a subunit of ATP synthase (HernandezZimbron et al. 2012; Pinho et al. 2014; Pozo Devoto and Falzone 2017). Reduced CCO activity, decreased mitochondrial membrane potential (MMP), and lower ATP generation are seen in brains of neurodegenerative disease patients. Mitochondrial complex I inhibitor 1-methyl4-phenyl-1,2,3,6-tetrahydropyridine (MPTP) or 1-methyl4-phenylpyridinium $\left(\mathrm{MPP}^{+}\right)$and the dopamine analogue 6-hydroxydopamine (6-OHDA) induce Parkinson's disease-like lesions and symptoms in animal models (Chinta et al. 2010; Federico et al. 2012). Impaired cytochrome c oxidase function, usually accompanied by the antioxidant deficit, leads to oxidative stress. Reactive oxygen species (ROS) are further generated when the protein aggregates cause microglial activation, creating a pro-inflammatory environment. The presence of chronic inflammation also ends up being cytotoxic towards the neurons (Pagani and Eckert 2011; Chen and Zhong 2014). At the same time, the pathogenesis of Parkinson's and Huntington's is also due to loss of inhibition on cortical glutamatergic neurons and excess amounts of glutamate in the synaptic cleft due to interference of glutamate uptake by astrocytes, causing prolonged stimulation of glutamate receptors, a phenomenon called excitotoxicity. Excitotoxicity further worsens the mitochondrial dysfunction in neurodegenerative diseases, causing an intramitochondrial $\mathrm{Ca}^{2+}$ overload and triggers apoptosis by the release of cytochrome $\mathrm{c}$ through the mitochondrial transition pore. Mitochondrial dysfunction hence appears to be a central mediator of neurodegenerative disease pathogenesis and disease progression (Dong et al. 2009; Cerella et al. 2010; Vaarmann et al. 2013).

Photobiomodulation (PBM), also known as low-level laser therapy, is the application of light at red to infrared wavelengths for therapeutic purposes. The fluence delivered is low enough to prevent any thermal or ablative effects. The PBM relies on a photochemical mechanism. A wavelength of 650-1200 nm light is most commonly used for the application, absorbed by chromophores present in the cells. The cytochrome c oxidase (CCO), mitochondrial electron chain transport complex IV absorbs wavelengths from 600 to about $900 \mathrm{~nm}$. Longer wavelengths are thought to be absorbed by water and light-sensitive ion channels such as the transient receptor potential (TRP) family, stimulating them to open. PBM can also reduce oxidative stress by dissociating the inhibitory nitric oxide (NO) from CCO (Hamblin 2016).

Due to its direct action on the mitochondria, PBM could be used as a potential therapeutic strategy for neurodegenerative diseases, which remain untreatable to date owing to the complex and layered aspects of the disease. PBM has been tested on neurodegenerative disease models such as Alzheimer's disease, Parkinson's disease, diabetic retinopathy, etc. In most cases, PBM shows beneficial effects by increasing mitochondrial function, reducing protein accumulation, reducing oxidative stress, and suppressing inflammation (Johnstone et al. 2016; Salehpour et al. 2018). PBM has mostly been used in Alzheimer's and Parkinson's disease animal models. PBM-treated animals showed improved behavioral and cognitive function, improved memory, and spatial learning compared to the deficits seen in neurodegenerative disease conditions (Oron and Oron 2016; Lu et al. 2017). Reduction in hyperphosphorylated tau, neurofibrillary tangles, and amyloid-beta $(\mathrm{A} \beta)$ plaques was also observed with PBM treatment (Purushothuman et al. 2014). In Parkinson's disease models, PBM significantly reduced motor impairment and the animals had better control of their motor skills. PBM also facilitated the preservation of dopaminergic fibers in the animals' brains (Oueslati et al. 2015). Additionally, PBM was found to decrease cerebrovascular damage after MPTP insult in mice (San Miguel et al. 2019).

For neurodegenerative diseases, the most commonly used PBM application mode is transcranial, where the light is applied directly to the head. However, there is also evidence that remote-PBM, where the light is applied to a part of the body distant from the intended target organ, is effective (Gordon and Johnstone 2019). A study by Ganeshan and colleagues found that remote-PBM preconditioning protects mice from MPTP-induced stress. The study found that preconditioning with PBM before MPTP administration 
mitigated the loss of dopaminergic neurons. The same study reported an investigation of transcriptomic changes in the brain after PBM treatment in normal animals, to understand how PBM made the animals more resistant to the neurotoxin. Multiple pathways were found to be involved in PBM therapy's protection against MPTP-induced stress. Genes involved in cell proliferation and migration, and genes belonging to JAK/STAT, C-X-C chemokine receptor 4 (CXCR4), and NRF2-mediated oxidative stress response, which regulates key antioxidant genes, were upregulated (Ganeshan et al. 2019).

There is limited knowledge of the molecular mechanisms behind these effects. This systematic review aims to identify the mechanisms by which PBM alters neurodegenerative disease aspects like oxidative stress, inflammation, cell death, and protein aggregation and to establish its potential as a therapeutic intervention capable of affecting the disease as a whole system.

\section{Methodology}

\section{Search Strategy}

Searches were performed in the electronic databases of PubMed and Scopus in March 2020 using different terms (Table 1). There was no date restriction, and sorting was done by "Best Match" criterion on PubMed.

\section{Inclusion Criteria}

Original research articles, both in vitro and in vivo studies that quantitatively or semi-quantitatively assessed the influence of PBM on any particular signaling pathway, growth factors and neurotrophic factors, genes and proteins involved in apoptosis, differential expression of genes and proteins involved in amyloidogenic protein degradation and production pathways, cytochrome c oxidase, ATP, genes involved in mitochondrial functions, and up- or downregulation of mitochondrial proteins in the cells, tissue, or animal with induced neurodegeneration, were included.

\section{Exclusion Criteria}

Reviews, book chapters, clinical trials, case reports, editorials, perspectives, letters, commentaries, reports, protocols, conference proceedings, foreign language, and research articles that did not use a photobiomodulation therapy on a test system/organism with induced neurodegeneration were excluded in the first phase after the title and/or abstractbased screening. Obtained full texts were further screened to exclude studies that did not fulfill the inclusion criteria. Those that did not clearly describe the method of administration of PBM were also excluded.

\section{Outcome Measures}

The primary outcome measures chosen were the influence of PBM on proteins involved in signaling pathways and cascades, transcription factors, growth factors and neurotrophic factors, genes and proteins involved in apoptosis, cytochrome c oxidase, ATP, genes and proteins involved in mitochondrial functions, and differential expression of genes and proteins in amyloidogenic protein production and degradation. The secondary outcome measures were other mitochondrial characteristics reported, oxidative stress, cytokine expression, and differential expression of other relevant genes and proteins.

\section{Study Selection}

Two authors independently performed title and abstract review, and full-text screening was carried out for studies remaining after phase 1 exclusion to identify the studies satisfying the inclusion criteria. Any differences were resolved by discussion and consensus.

Table 1 Search terms used during the study

\footnotetext{
PubMed (Low level laser therapy) AND neurons; (low level laser therapy[MeSH Major Topic]) AND neurodegenerative disease[MeSH Major Topic]; (low level laser therapy) AND neurodegenerative disease[MeSH Major Topic]; (low level laser therapy) AND neurogenerative disease; (photobiomodulation) AND neurons; (photobiomodulation) AND neurodegenerative disease; (photobiomodulation) AND neurodegenerative disease[MeSH Major Topic]; (low level laser therapy) AND parkinson's disease; (photobiomodulation) AND parkinson's disease; (low level laser therapy) AND parkinson's disease; (photobiomodulation) AND parkinson's disease; (low level laser therapy) AND huntington's disease; (photobiomodulation) AND huntington's disease; (low-level laser therapy) AND multiple sclerosis; (photobiomodulation) AND multiple sclerosis

Scopus "Photobiomodulation" AND neurodegenerative disease; "low level laser therapy" AND neurodegenerative disease; "photobiomodulation" AND neurons; "low level laser therapy" AND neurons; "photobiomodulation AND parkinson's disease"; "low level laser therapy" AND parkinson's disease; "photobiomodulation AND huntington's disease"; "low level laser therapy" AND huntington's disease; "photobiomodulation AND parkinson's disease"; "low level laser therapy" AND parkinson's disease
} 


\section{Data Extraction}

In the studies meeting inclusion criteria, data were retrieved using a standard form to record the type of device, the wavelength used and fluence delivered, the test system or model organism used, a substance used to induce neurodegeneration, method of administration, control intervention, and outcomes. Due to the diversity in methodologies used and the results measured, a meta-analysis was not possible.

\section{Results and Discussion}

A total of 20 studies were finally included for data extraction and analysis in this review based on the inclusion criteria adopted. The workflow followed for the selection of eligible articles is shown in Fig. 1. Of these, 11 studies tested PBM with Alzheimer's disease models, 2 used PBM with Parkinson's disease models, 1 used PBM for in experimental autoimmune encephalomyelitis (a model of MS), and 2 assessed PBM for diabetic retinopathy. The four others did not use a model of any particular disease but used agents like hydrogen peroxide (oxidative stress), potassium cyanide and tetrodotoxin (neurotoxins), and NMDA, kainate, and glutamate (excitotoxicity) to induce neuronal cell degeneration (Table 2).
The data suggest that PBM alleviates the symptoms of neurodegenerative disease and slows down disease progression. PBM can preserve the normal state of the cells when stress is induced or influence cellular functioning to counter the neurodegenerative conditions. PBM therapy is capable of coaxing stressed neurons into producing neurotrophic factors like brain-derived neurotrophic factor (BDNF) and glial cell line-derived neurotrophic factor (GDNF) (Meng et al. 2013; $\mathrm{Gu}$ et al. 2017; Heo et al. 2019) and rescuing neurons from apoptosis by altering the expression and activity of pro- and anti-apoptotic proteins like Bcl2, Bcl-xL, Bax, and caspases (Zhang et al. 2008, 2012; Muili et al. 2013; Lu et al. 2017). It is also effective in reducing the amyloid plaque formation either by stimulating microglial phagocytosis of the protein aggregates or by altering the expression of enzymes involved in the amyloid peptide production and degradation pathways (Song et al. 2012; Zhang et al. 2020). The review also reaffirms the effect of PBM on improving the deterioration often seen in mitochondrial functioning in neurodegenerative diseases (Wong-Riley et al. 2005; De Taboada et al. 2011; Purushothuman et al. 2014; Huang et al. 2014; Lu et al. 2017; Zhang et al. 2020). The effects of PBM can be explained sequentially to begin with the stimulation of mitochondrial function leading to increased ATP, cAMP production, and $\mathrm{Ca}^{2+}$ signaling, which then activate several intracellular signaling molecules and pathways to alter gene and protein expression and activity.
Fig. 1 Flow diagram shows the selection process of eligible articles that applying photobiomodulation against neurodegenerative diseases

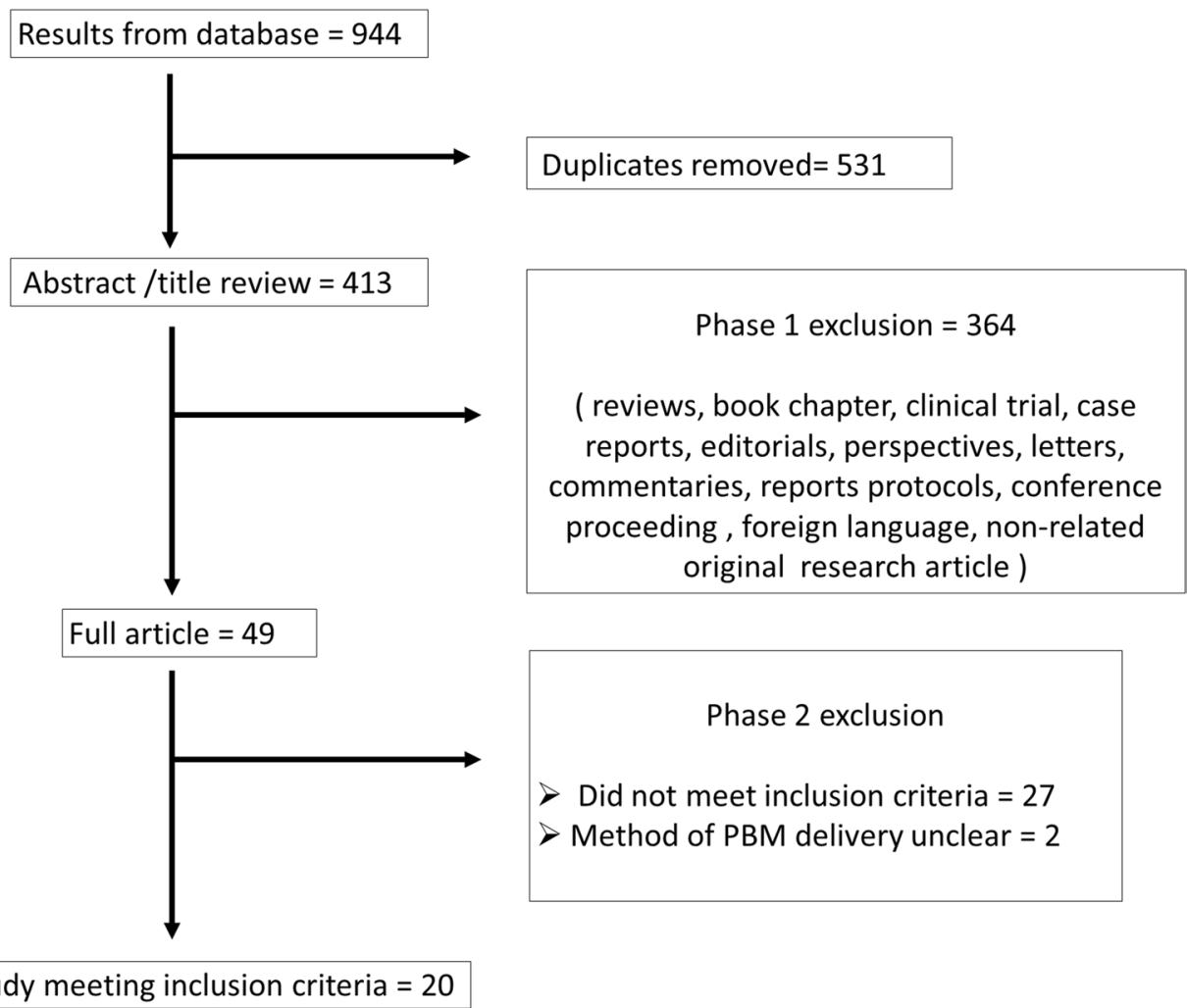




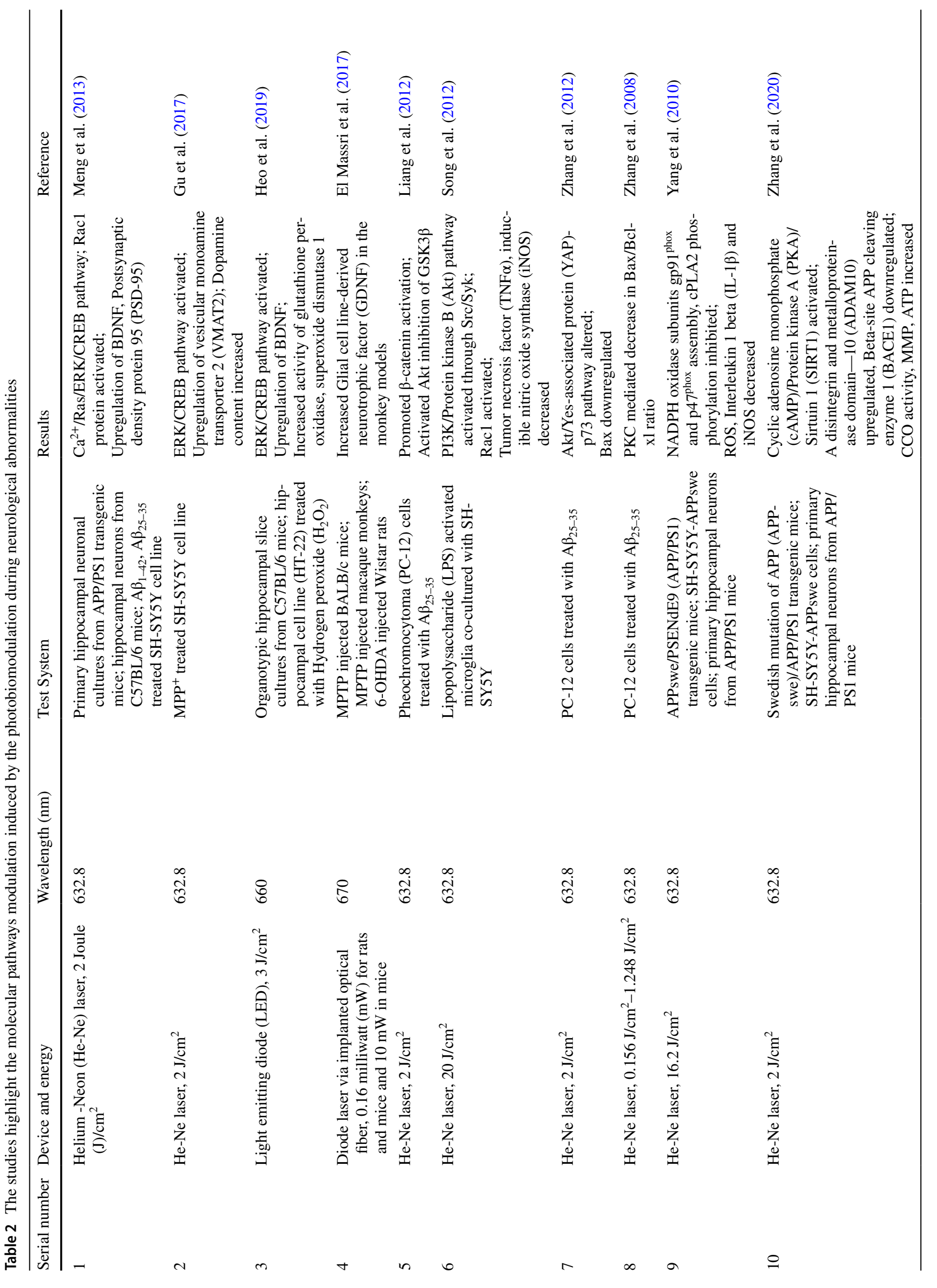




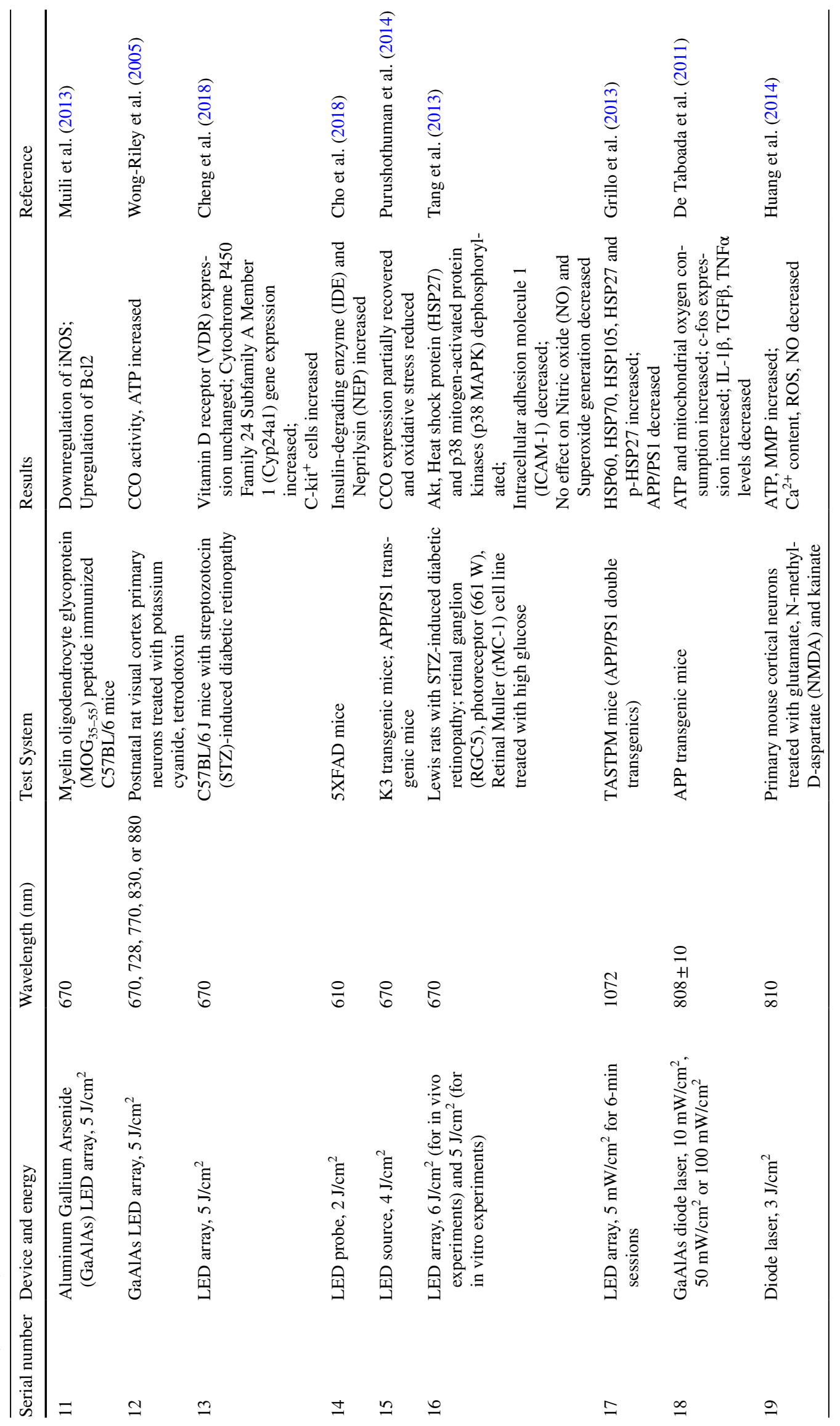




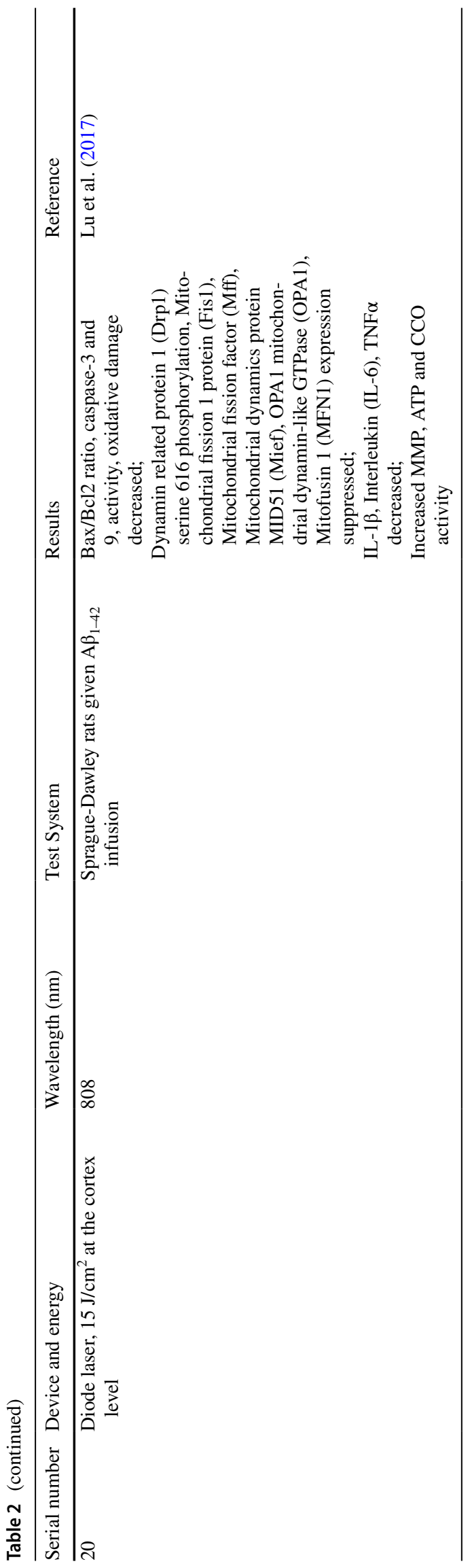

\section{PBM Stimulates Mitochondrial Activity}

PBM exerts a photochemical effect through the stimulation of mitochondrial cytochrome c oxidase ( $\mathrm{CCO}$ ). In neurodegenerative diseases, neurons experience mitochondrial dysfunction, loss of mitochondrial membrane potential (MMP), and depletion of ATP. PBM reverses the damage to the mitochondria fully or partially by stimulating $\mathrm{CCO}$ function and oxidative phosphorylation to restore MMP and raise ATP production (Wong-Riley et al. 2005; De Taboada et al. 2011; Huang et al. 2014; Zhang et al. 2020). It has been hypothesized that activation of $\mathrm{CCO}$ by PBM works by releasing nitric oxide (NO) from $\mathrm{CCO}$, generating reactive oxygen species (ROS), and triggering NO signaling pathways (Hamblin 2016). This may not hold when PBM is used on cells already under stress (Huang et al. 2013), since the data reviewed here show a decrease in oxidative stress and NO signaling (Yang et al. 2010; Song et al. 2012; Huang et al. 2014).

\section{Mitochondrial Stimulation Triggers Several Signaling Pathways}

PBM is known to activate multiple pathways such as ERK/ CREB (Meng et al. 2013; Gu et al. 2017; Heo et al. 2019), cAMP/PKA/SIRT1 (Zhang et al. 2020), PKC (Zhang et al. 2008), Src/Syk/PI3K/Akt (Song et al. 2012), and Akt/ GSK3 $\beta / \beta$-catenin (Liang et al. 2012), involved in various molecular networks in the cellular system.

From the data, three significant paths through which the above-mentioned signaling cascades might be activated after PBM by CCO stimulation could be identified as follows:

1. Calcium ions $\left(\mathrm{Ca}^{2+}\right)$

Increased ATP production and release due to $\mathrm{CCO}$ stimulation by PBM can induce $\mathrm{Ca}^{2+}$ influx through the purinergic $\mathrm{P} 2 \mathrm{X}$ receptors. Extracellular ATP induces $\mathrm{Ca}^{2+}$ influx by binding to $\mathrm{P} 2 \mathrm{X}$ receptors or triggering the production of $\mathrm{IP}_{3}$ through DAG when the ATP binds to $\mathrm{P} 2 \mathrm{Y}$ receptors instead. Activated $\mathrm{IP}_{3} \mathrm{Rs}$ release $\mathrm{Ca}^{2+}$ from endoplasmic reticular (ER) stores (Wei et al. 2019). $\mathrm{Ca}^{2+}$ influx and increase in intracellular $\mathrm{Ca}^{2+}$ can activate PKC. PKC further leads to Raf/MEK/ERK signaling. $\mathrm{Ca}^{2+}$ can also activate PI3K/Akt through calmodulin (Moccia et al. 2019). In the data collected for this review, one study confirms that the activation of ERK pathway required $\mathrm{Ca}^{2+}$ release from intracellular stores (Fig. 2) (Meng et al. 2013). In contrast, PBM also acts as a neuroprotective against excitotoxic cell death by preserving the mitochondrial function and decreasing the toxic levels of intracellular $\mathrm{Ca}^{2+}$ content (Huang et al. 2014).

2. Cyclic adenosine monophosphate (cAMP) 
Fig. 2 Effect of PBM through increased extracellular ATP and intracellular $\mathrm{Ca}^{2+}$. 1- Light is absorbed by mitochondrial CCO. 2-ATP production is increased. 3-ATP produced is secreted out and extracellular ATP increases. 4-Extracellular ATP binds to P2X receptor allowing $\mathrm{Ca}^{2+}$ influx. 5-Extracellular ATP binds to $\mathrm{P} 2 \mathrm{Y}$ receptor which triggers the release of $\mathrm{Ca}^{2+}$ from endoplasmic reticulum (ER) stores. 6-Intracellular $\mathrm{Ca}^{2+}$ level increases, activating PKC and ERK pathways or PI3K/Akt through calmodulin $(\mathrm{CaM})$

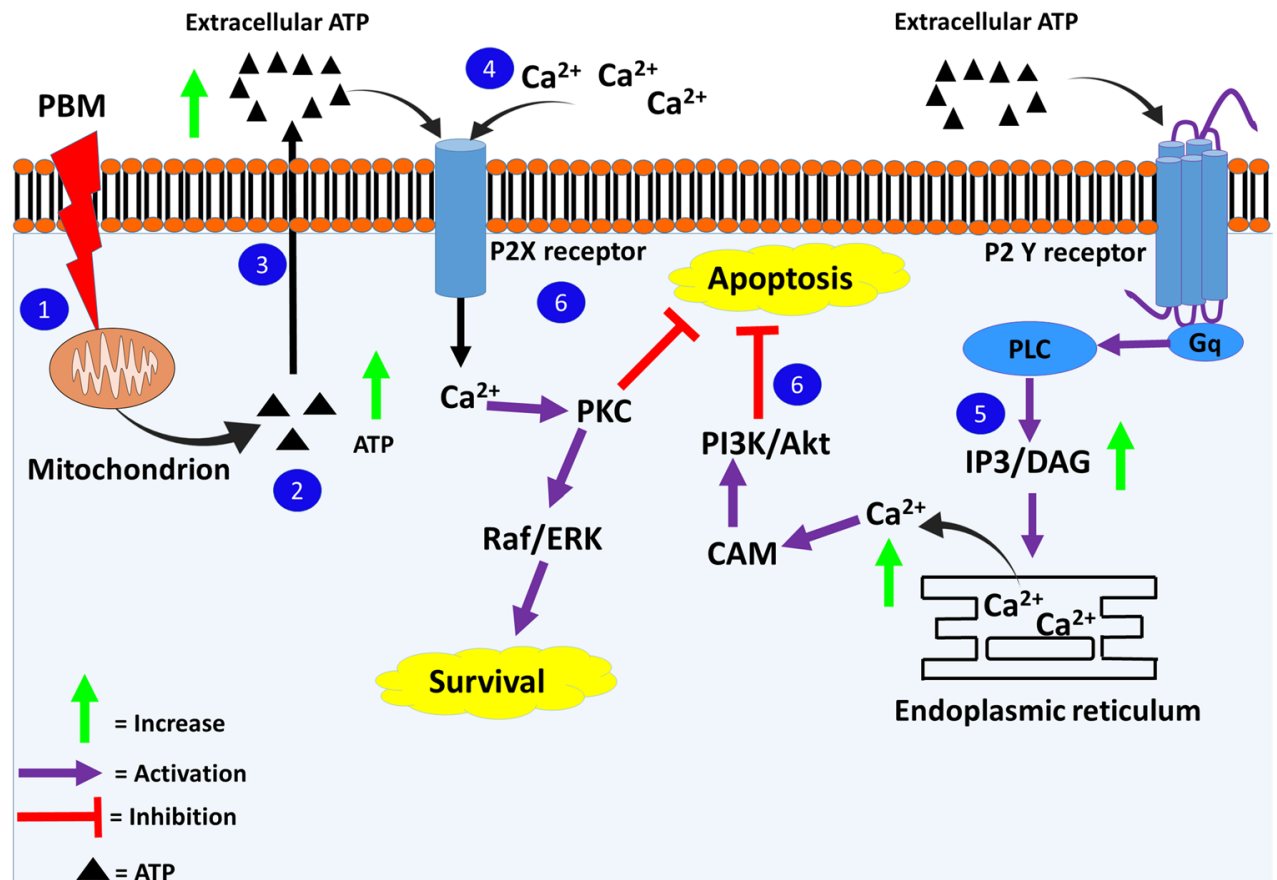

Cytoplasm
PBM stimulates the activity of CCO, raising MMP, and increasing the production of ATP in neurodegenerative disease models (Wong-Riley et al. 2005; Purushothuman et al. 2014; Huang et al. 2014). Adenyl cyclase can convert ATP to cAMP (Zhang et al. 2020). B-Raf is activated by cAMP through proteins like PKA, Ras, or
Src. B-Raf can further activate ERK1/2. These mediators can also activate PI3K/Akt or SIRT1 (Dumaz and Marais 2005; Goldsmith and Dhanasekaran 2007). The above-mentioned study by Z. Zhang et al. confirmed the activation of SIRT1 through ATP and cAMP (Fig. 3) (Zhang et al. 2020).
Fig. 3 Effect of PBM through cAMP and ROS. 1-Light is absorbed by mitochondrial CCO. 2 - ROS is produced and the ROS can activate $\mathrm{Src}$ and PI3K/Akt pathway. 3-ATP production is increased. 4Adenyl cyclase converts ATP to cAMP. And the second messenger cAMP can activate PKA and Ras further leading to SIRT1 and ERK signaling

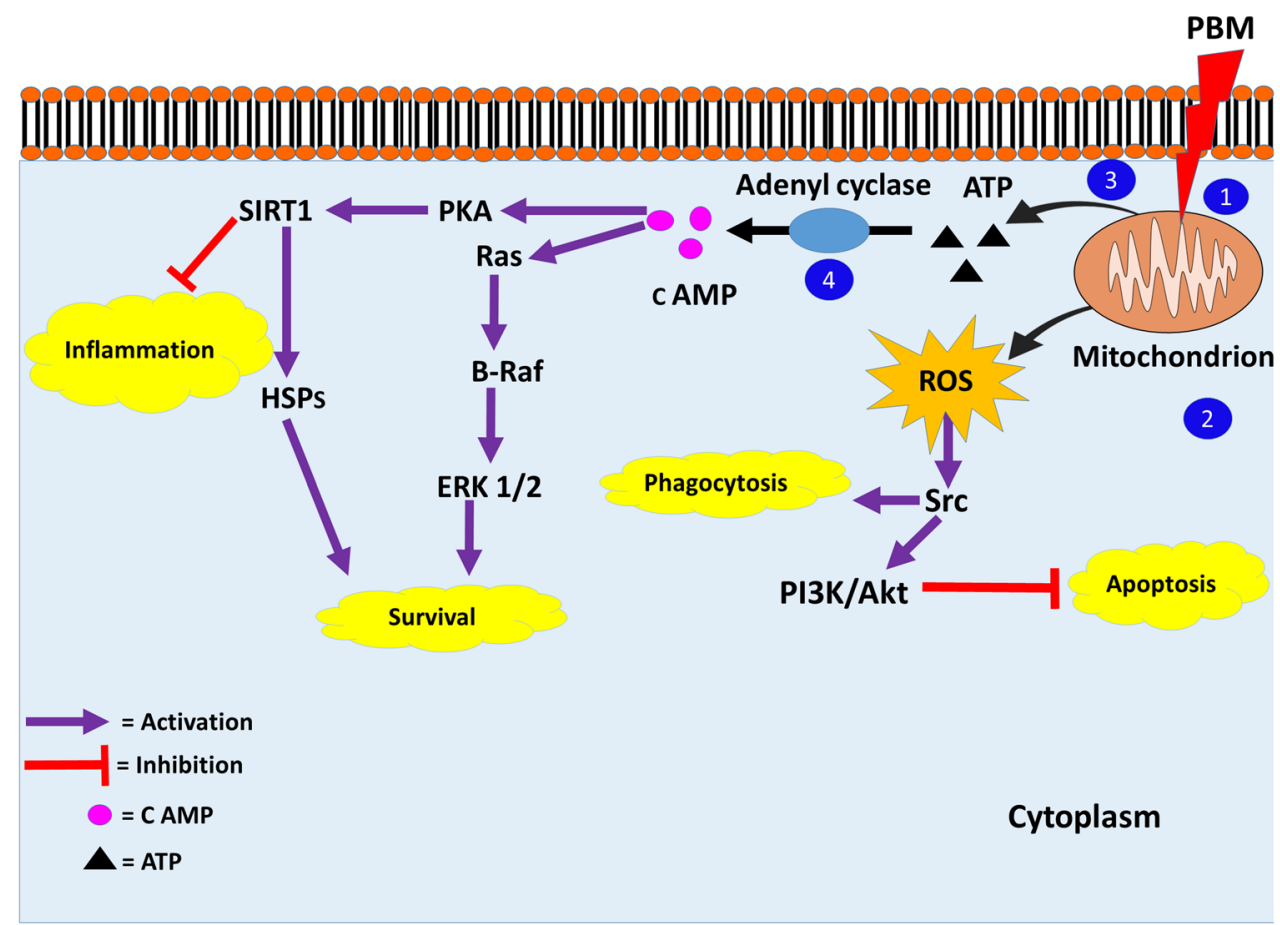


3. Reactive oxygen species (ROS)

CCO stimulation by PBM is hypothesized to be involved in NO release and generation of ROS. ROS signaling leads to the activation of pathways like NF-kB, NRF2, and PI3K/Akt (Fig. 3) (Zhang et al. 2016). Although none of the studies included for this review report an increase in NO signaling or ROS, an initial short-lived rise in oxidative species might be possible. PBM has been found to increase ROS when used in normal cell lines but decreases them in cells subjected to stress (Huang et al. 2013).

\section{Intracellular Signaling Molecules and Pathways}

\section{MAPK Pathway}

A study by Chengbo Meng and others reported that intracellular $\mathrm{Ca}^{2+}$ levels rose by release from ER stores following PBM, which activated Ras kinase activity and thus the ERK/MAPK cascade in mouse Alzheimer's disease model. The transcription factor CREB was the downstream effector of the Ras/ERK pathway (Meng et al. 2013). Activation of ERK/CREB after PBM was also confirmed by two other independent studies in HT-22 cells under oxidative stress and $\mathrm{MPP}^{+}$-treated SH-SY5Y cells (Gu et al. 2017; Heo et al. 2019).

One study investigated the phosphorylation of p38 in retinal ganglion (RGC5) cells line under high glucose conditions to test the use of PBM for diabetic retinopathy, where it was effective in suppressing the increased phosphorylation of p38 (Tang et al. 2013). P38 is a member of the MAPK family, inducible by pro-inflammatory cytokines and cellular stress like oxidative stress and radiation, and is a critical player in the regulation of apoptosis (De Zutter and Davis 2001; Yang et al. 2007). P38 MAPK is known to mediate apoptosis induced by the withdrawal of neurotrophic factors, often associated with neurodegenerative diseases (Kummer et al. 1997; Weissmiller and Wu 2012). Bim, a pro-apoptotic member of the $\mathrm{Bcl} 2$ family, is phosphorylated by p38 (Cai et al. 2006). P38 is also known to activate the pro-inflammatory NF-kB pathway (Hoesel and Schmid 2013). Hence, p38 dephosphorylation is beneficial in neurodegeneration.

\section{PI3K/Akt Pathway}

The PI3K/Akt pathway might be a focal point in PBM-stimulated effects. The pathway performs its anti-apoptotic functions at several levels, recruiting various downstream effectors. It inhibits p53-mediated apoptosis and enhances the transcription of anti-apoptotic genes by lifting the inhibition on nuclear factor kappa-light-chain-enhancer of activated B cells (NF-kB) and $\beta$-catenin, as well as inhibiting the forkhead box protein (FOXO) transcription factors that activate pro-apoptotic genes like Bcl2-like protein 11 (Bim) and BCL2-associated X (Bax) (Zhang et al. 2013). Akt increases anti-apoptotic Bcl2 expression by activating CREB/GATAbinding factor 1 (GATA1) (Jafari et al. 2019). Akt can also interfere with apoptosis by lifting the inhibition of hypoxiainducible factor 1 (HIF-1) and increasing the transcription of heat shock protein (HSP) genes (Beurel and Jope 2006). An Akt pathway through which PBM prevents apoptosis is the $\mathrm{Akt} / \mathrm{GSK} 3 \beta / \beta$-catenin cascade. PBM activated Akt and its phosphorylation (inactivation) of GSK3 $\beta$. The T cell factor (TCF)/lymphoid enhancer factor (LEF) proteins are the major end-point effectors of the $\mathrm{Wnt} / \beta$-catenin signaling pathway, which promotes transcription of genes for survival (Liang et al. 2012; Herbst et al. 2014).

Another study reported PBM activation of PI3K/ Akt as essential for protecting PC-12 cells from $\mathrm{A} \beta$ (25-35)-induced apoptosis (Zhang et al. 2012) through Yes-associated protein (YAP). In LPS-activated microglia, PBM brought about neuroprotective and anti-inflammatory responses, decreasing cytotoxicity to SH-SY5Y cells cocultured with the LPS-activated microglia. The effects were reported to be mediated by the Src/Syk activation of the PI3K/Akt signaling pathway (Song et al. 2012).

\section{SIRT1 Pathway}

A member of the sirtuin family, SIRT1 is a deacetylase called into action during stress conditions, especially metabolic stress (Gerhart-Hines et al. 2011). PBM activated the cAMP/PKA/SIRT1 pathway in APP/PS1 transgenic mice, primary neurons, and SH-SY5Y cells containing the APPswe mutation. SIRT1 further deacetylated and activated the transcriptional inducer retinoic acid receptor beta (RAR- $\beta$ ) and the transcriptional coactivator PGC-1 $\alpha$ (Zhang et al. 2020). There was a decrease in the production of $A \beta$ peptides, while the expression of APP was unchanged. SIRT1 can work to suppress apoptosis by inhibiting the activity of p53, inducing HSPs through Heat shock factor 1 (HSF1), and activating the FOXO family of transcription factors (Raynes et al. 2013).

\section{Heat Shock Proteins (HSPs)}

Heat shock proteins are stress-induced proteins that mediate protein homeostasis and protein folding by acting as molecular chaperones (Meng et al. 2018). They suppress apoptosis caused by triggers such as oxidative stress, hyperthermia, cytotoxicity, and inflammation. Being essential for protein folding, the neuroprotective role of HSPs in neurodegeneration seems plausible given that many neurodegenerative diseases like Alzheimer's 
disease, Parkinson's disease, Huntington's disease, amyotrophic lateral sclerosis, and spinocerebellar ataxia all have misfolded proteins as a common disease mechanism. HSP70, in particular, has been shown to decrease the aggregation of mutant proteins with expanded polyQ tracts like huntingtin and also of $\alpha$-syn, $A \beta$, and superoxide dismutase 1 (SOD1) (Turturici et al. 2011). HSPs control apoptosis at several levels, such as regulating the expression of pro- and anti-apoptotic proteins, activating the PI3K/Akt pathway (Havasi et al. 2008) and NF-kB pathway (Meng et al. 2018) which further regulates antiapoptotic genes such as Bcl2 (Hoesel and Schmid 2013), or inactivate the pro-apoptotic JNK pathway (Stetler et al. 2009). HSPs are also protectors against cell death caused by the withdrawal of neurotrophic factors, which are known to be required for the survival and growth of neurons. HSP105 has even demonstrated the ability to induce the production of the neurotrophic factor BDNF (Stetler et al. 2009; Hashikawa et al. 2017). PBM was shown in one study to have reduced amyloid peptide production and hyperphosphorylated tau in the Alzheimer's disease model, TASTPM mice, by upregulating HSPs. HSP27 and p-HSP27, HSP60, HSP70, and HSP105 were found to be increased while no significant difference was observed in HSP40 and HSP90 (Grillo et al. 2013). Contrary to this, PBM in high glucose-treated RGC5 cells, a model for diabetic retinopathy, decreased p-HSP27, which was found to be increased in cells that did not receive PBM intervention (Tang et al. 2013). The opposite results seen in the two studies may be attributed to a difference in the disease, the model, as well as the PBM characteristics such as wavelength, $1072 \mathrm{~nm}$, and $670 \mathrm{~nm}$ LED light, respectively.

Further, another signaling component found to be required for PBM's anti-apoptotic effect is PKC. PBM was reported to protect against apoptosis in $A \beta$-treated PC-12 cells by activation of PKC (Zhang et al. 2008). It is known that $\mathrm{PKC}$ can modulate the activity of $\mathrm{Bcl}$ proteins by phosphorylating them directly and altering their interactions with Bax, or it may act by activating the Raf/ MEK/ERK cascade (Deng et al. 2000).

Rat primary cortical astrocytes when pre-treated with PBM before exposure to $A \beta_{1-42}$ experienced lesser oxidative stress and confirmed that PBM could decrease phosphorylated levels of the phospholipase cPLA2 and the activity of NADPH oxidase, a major contributor to oxidative stress. cPLA2 can lead to ROS production and inflammation through the synthesis of arachidonic acid, which further paves the way for the production of leukotrienes and prostaglandins. Hence, decreased p-cPLA2 is a mechanism of the anti-oxidative and anti-inflammatory effects of PBM (Yang et al. 2010; Sun et al. 2014).

\section{From Signaling Pathways to Therapeutic Effects}

\section{Maintenance and Activity of Neurons}

PBM was found to attenuate dendrite atrophy caused by Amyloid-beta $(A \beta)$ in hippocampal neurons. PBM raised the levels of brain-derived neurotrophic factor (BDNF), significantly reduced in the Alzheimer's disease models, APP/PS1 transgenic mice, primary hippocampal neurons exposed to $\mathrm{A} \beta$ peptide, and hippocampal neurons from APP/ PS1 transgenic mice embryos. BDNF was essential for the prevention of dendrite atrophy (Meng et al. 2013). BDNF is known to be involved in the growth and survival of neurons and neurogenesis and promotes excitatory synaptic transmission. Loss of BDNF negatively affects learning and memory (Binder and Scharfman 2004), and the upregulation seen with PBM may help not only the survival of the neurons but also alleviate cognitive symptoms of Alzheimer's disease. The transcription of BDNF can be activated by $\mathrm{Ca}^{2+}$ influx and $\mathrm{Ca}^{2+}$-dependent activation of ERK and cAMP/ PKA pathways (Zheng et al. 2012). The BDNF upregulation through Ras/ERK and binding of phosphorylated CREB to BDNF promoter was confirmed by the above-mentioned study in Alzheimer's disease model and in another study of hippocampal neurons under oxidative stress (Meng et al. 2013; Heo et al. 2019). Glial cell line-derived neurotrophic factor (GDNF) was also found to be upregulated by PBM in monkey models of Parkinson's disease (El Massri et al. 2017).

Vitamin D is also known to play a pivotal neuroprotective role against neurodegenerative disease pathogenesis. The vitamin D receptor (VDR) regulates the transcription of several genes essential for neuronal survival, functioning, and maintenance, such as the neurotrophic agents NGF and GDNF. VDR also protects against calcium excitotoxicity by regulating the expression of the L-type voltage-sensitive calcium channels. In addition, vitamin $D$ also promotes $A \beta$ phagocytosis (Gezen-AK et al. 2014; Banerjee et al. 2015). A study investigated the effect of PBM on VDR signaling in a model of diabetic retinopathy, the degeneration of retinal ganglion cells as a complication of diabetes. PBM raised the messenger RNA (mRNA) of CYP24A1, a gene regulated by VDR, compared to its subnormal expression in the disease condition. However, no difference was observed in the expression of VDR mRNA, suggestive of PBM influencing the VDR activity rather than expression. This area requires further investigation. The study also reported an increase in hematopoietic stem cells $\left(\mathrm{CD} 45^{-} / \mathrm{c}-\mathrm{kit}^{+}\right)$in circulation. Although it was not attributed to the beneficial effects of PBM against diabetic retinopathy, it confirms the mobilization of stem cells by PBM (Cheng et al. 2018).

$\mathrm{PBM}$ restored the dopamine content in $\mathrm{MPP}^{+}$exposed cells by increasing the expression of the dopamine 
transporter VMAT2 and tyrosine hydroxylase, the enzyme responsible for producing dopamine. The expression of VMAT2, regulated by the ERK/CREB pathway, is essential for the maintenance and release of monoamines like dopamine and serotonin in monoaminergic neurons of the central nervous system and its expression, thus highlighting the neuroprotective role of PBM (Eiden and Weihe 2011; Gu et al. 2017; El Massri et al. 2017). Besides, PBM also improved neuronal transmission by upregulation of PSD-95, a scaffold protein required for assembly of neurotransmitter receptors and other signaling elements for postsynaptic transmission (Keith 2008; Meng et al. 2013). The expression of the transcription factor, c-fos, induced by neuronal activity (Chung 2015), was also raised by PBM (De Taboada et al. 2011).

Anti-inflammation In LPS-activated microglia, PBM brought about neuroprotective and anti-inflammatory responses, decreasing cytotoxicity to SH-SY5Y cells cocultured with the LPS-activated microglia. The effects were reported to be mediated by the Src/Syk activation of the PI3K/Akt signaling pathway. The effectors of the neuroprotective effect observed were myeloid differentiation primary response 88 (MyD88) and Ras-related C3 botulinum toxin substrate 1 (Rac1) proteins (Song et al. 2012). MyD88 is an adaptor protein involved in the signal transduction from tolllike receptors (TLRs) and IL-1 receptors (Deguine and Barton 2014). Rac1 is central to actin dynamics, essential for axonal growth and survival, and also plays a role in phagocytosis by promoting actin polymerization. Rac1 also has a function in regulating the ROS-producing nicotinamide adenine dinucleotide phosphate (NAPDH) oxidase (NOX) activity (D'Ambrosi et al. 2014). PBM promoted the degradation of MyD88, alleviating the pro-inflammatory conditions and activated Rac1, promoting F-actin accumulation and polymerization, in support of the phagocytic ability of the microglia (Song et al. 2012). The Rac1 activation might improve microglial phagocytosis of amyloid plaques.

The pro-inflammatory cytokines IL-1 $\beta$, IL-6, TGF $\beta$, and TNF $\alpha$ were found to be decreased by PBM (Yang et al. 2010; De Taboada et al. 2011; Song et al. 2012; Lu et al. 2017). These cytokines may be suppressed by p38 dephosphorylation seen with PBM (Bachstetter and Van Eldik 2010; Tang et al. 2013). In rat primary cortical astrocytes, PBM inhibited $\mathrm{A} \beta$ induced ROS from NOX (Yang et al. 2010). ROS from NOX can induce several molecules and signaling pathways like p38 MAPK/Phospholipase A2 (cPLA2), leading to inflammation (Sun et al. 2014). The study on astrocytes confirmed that PBM could decrease p-cPLA2. The ROSproducing nitric oxide synthase (iNOS) expression was also lowered (Yang et al. 2010; Song et al. 2012).

Anti-apoptosis PBM prevented apoptosis by increasing $\mathrm{Bcl} 2$ and $\mathrm{Bcl}-\mathrm{xL}$, decreasing Bax and suppressing the activ- ity of caspase-3 and caspase-9 (Zhang et al. 2008, 2012; Muili et al. 2013; Lu et al. 2017). In A $\beta$-treated PC-12 cells, the downregulation of $\mathrm{Bax}$ required $\mathrm{PKC}$ activation by $\mathrm{PBM}$ (Zhang et al. 2008). PBM also downregulated Bax through Akt activation and prevention of YAP-p73 complex formation (Zhang et al. 2012). YAP mediates apoptosis through its nuclear translocation and interaction with the transcription factor $\mathrm{p} 73$ and increases the expression of pro-apoptotic genes like Bax (Bertini et al. 2009). PBM activated Akt, which phosphorylates YAP and prevents YAP-p73 complex formation, suppressing the expression of Bax (Zhang et al. 2012).

Another identified mechanism through which PBM prevents apoptosis in A $\beta$-treated PC-12 cells is by lifting $\beta$-catenin inhibition. PBM, through the phosphorylation of Akt, leads to inactivation of GSK3 $\beta$ which normally inhibits $\beta$-catenin. PBM promoted $\beta$-catenin translocation to the nucleus and increased its transcriptional activity (Liang et al. 2012). Binding of $\beta$-catenin to the DNA-binding $T$ cell factor/lymphocyte enhancer factor (TCF/LEF), causes the recruitment of coactivators and dismissal of corepressors normally bound to TCF/LEF in the absence of $\beta$-catenin and turns on the transcription of genes responsible for proliferation and survival such as MYC proto-oncogene (MYC) and ABCB 1 (Herbst et al. 2014).

Antioxidant Capacity and Mitochondrial Preservation Total antioxidant capacity was increased and the decrease in the antioxidants glutathione peroxidase (GPx), heme oxygenase 1 (HO-1), and superoxide dismutase (SOD1 and SOD2) was recovered following PBM treatment in animal models of Alzheimer's disease and diabetic retinopathy, as well as SH-SY5Y cells under oxidative stress (Tang et al. 2013; Lu et al. 2017; Heo et al. 2019). PBM suppresses the prooxidant NO signaling by downregulating inducible NO synthase (NOS) (Yang et al. 2010; Song et al. 2012; Muili et al. 2013; Huang et al. 2014).

PBM also exerted its anti-oxidative effect by lowering the activity of glucose-6-phosphate dehydrogenase (G6PDH) that produces NADPH. Decreased availability of NADPH could be responsible for the lower activity of the ROSproducing NADPH oxidase (NOX) (Lu et al. 2017). While $\mathrm{A} \beta$ induced the assembly of NOX subunits gp91 ${ }^{\text {phox }}$ and $\mathrm{p} 47^{\text {phox }}$ and the production of ROS, PBM prevented their colocalization and attenuated ROS production (Yang et al. 2010). Though the study did not investigate the mechanism by which PBM prevented NOX assembly, it is known previously that the assembly of NOX subunits begins with phosphorylation of $\mathrm{p} 47^{\text {phox }}$ by PKC (Rastogi et al. 2017).

The shift in mitochondrial dynamics towards the fission and fragmentation and functional loss of mitochondria is often seen in neurodegenerative diseases (Gao et al. 2017). In addition to improving mitochondrial oxidative 
phosphorylation by enhancing the activity of $\mathrm{CCO}$, raising MMP, and improving ATP production, $\mathrm{PBM}$ affects the mitochondrial dynamics by altering the fusion and fission processes. PBM treatment preserves the expression of fusion proteins and prevents the shift towards fission and fragmentation. The expression of proteins controlling mitochondrial dynamics was influenced by PBM, where fission proteins like Fis 1, Mff, and Mief were decreased. Drp1-S616 (serine 616) phosphorylation (fission promoting) was repressed, and Drp1-S637 (serine 637) phosphorylation (fusion promoting) was supported, Drp1-Fis1/Mff interactions were prevented, and expression and localization of the other fission proteins OPA1 and MFN1 were attenuated by irradiation, allowing the preservation of mitochondrial integrity (Wong-Riley et al. 2005; De Taboada et al. 2011; Purushothuman et al. 2014; Huang et al. 2014; Lu et al. 2017; Zhang et al. 2020). SIRT1, activated by PBM (Zhang et al. 2020), is also previously known to support mitochondrial biogenesis (Xu et al. 2018; Zhou et al. 2018). Hence, improvement in mitochondrial health through PBM therapy could also be through this mechanism.

Reduction in Amyloid Plaque Burden PBM is effective in reducing the amyloid plaque burden either by stimulating microglial phagocytosis of the protein aggregates or by altering the expression of enzymes involved in the amyloid peptide production and degradation pathways (Song et al. 2012; Zhang et al. 2020). PBM stimulates microglia through Rac1 activation and promotes phagocytosis while promoting an anti-inflammatory environment, thus avoiding inflammation-induced cytotoxicity (Song et al. 2012). In addition, PBM stimulates GSK3 $\beta$ inhibition (Liang et al. 2012), which can further help towards preventing tau hyperphosphorylation (Zheng et al. 2002).

In APP/PS1 transgenic mice primary neurons and SHSY5Y cells containing the APPswe, there was a decrease in the production of $A \beta$ peptides, while the expression of APP was unchanged. Upon further investigation, the study reported that PBM activated the cAMP/PKA/SIRT1 pathway and altered APP processing by upregulating the $\alpha$-secretase ADAM10 and downregulating the $\beta$-secretase BACE1. SIRT1 was responsible for these changes by deacetylating and activating retinoic acid receptor beta (RAR- $\beta$ ) and PGC-1 $\alpha$ (Zhang et al. 2020). Retinoic acid receptor (RAR) alpha and beta are inducers of ADAM10 promoter activity (Endres and Deller 2017), while PGC-1 $\alpha$ suppresses BACE1 expression (Katsouri et al. 2011; Wang et al. 2013). Also, PBM upregulated the A $\beta$ degrading IDE and NEP enzymes in Alzheimer's disease transgenic mice (Cho et al. 2018).

PBM Treatment Activates a Multidimensional Stress Response System in the Cells The stress response action of PBM can be attributed to mainly a suppression of inflamma- tion through dephosphorylation of p38 MAPK (Tang et al. 2013), inhibition of apoptosis through activation of SIRT1 (Zhang et al. 2020) and HSPs (Grillo et al. 2013), rescue from oxidative stress, and significant preservation of mitochondrial functioning (Huang et al. 2014; Purushothuman et al. 2014; Lu et al. 2017) as per previous studies results mentioned in this review. While the mechanism behind PBM regulation of antioxidant proteins is not well understood, we can postulate that the PKC and PI3K/Akt pathways modulated by PBM, also to some extent, control the anti-oxidant response by activation of NRF2/Anti-oxidant response element (ARE) signaling (Baird and DinkovaKostova 2011). PBM hence can support multiple cascades to preserve neuronal function and integrity and decelerate disease progression.

An interesting effect of PBM that remains unanswered is the mechanism by which PBM alters the expression and activity of the genes and proteins involved in mitochondrial dynamics to alleviate mitochondrial stress. It is well known that PBM decreases mitochondrial fragmentation and so it remains to be seen what factors play into the influence of PBM on mitochondrial dynamics (Lu et al. 2017; Wang et al. 2019).

A stress response mechanism commonly tested in PBM interventions is the NF-kB pathway. NF-kB is both proinflammatory and anti-apoptotic (Liu et al. 2017). Previous studies using PBM treatment for trauma and injury have shown that PBM decreases the activation of NF-kB (Rizzi et al. 2006; Lee et al. 2018). However, it is also postulated that ROS and NO generated by PBM treatment trigger the activation of NF-kB (Chen et al. 2011; Kumar et al. 2019). $\mathrm{NO}$ generation is hypothesized to occur when PBM activates $\mathrm{CCO}$ by displacement of $\mathrm{NO}$, which generally inhibits $\mathrm{CCO}$ (Hamblin 2016). The included studies in the current review did not test the influence of PBM on NF-kB specifically. However, we can gather from the data that PBM suppressed NO signaling (Yang et al. 2010; Song et al. 2012; Muili et al. 2013; Huang et al. 2014), and these results may be extrapolated to say that NF-kB signaling might be suppressed under PBM influence in neurodegeneration conditions.

PBM Influences an Interconnected Network of Cellular Signaling Towards a Beneficial Effect The data indicate that the effects of PBM are not mediated linearly by a single signaling cascade. PBM affects multiple pathways and multiple proteins, each of which often regulates very different functions in the same cell type. For instance, one of the proteins found to be activated by PBM in neurodegeneration models is the Rac1 GTPase (Song et al. 2012; Meng et al. 2013), a protein essential for axonal growth, stability, and phagocytosis. Rac1 inhibition causes actin dysfunction and motor neuron degeneration, but over-activation can cause the production of NOX-mediated ROS (D'Ambrosi et al. 2014), 
triggering NF-kB (Chen et al. 2011; Kumar et al. 2019), causing the production and release of pro-inflammatory cytokines and oxidative stress (Liu et al. 2017). Hence, the activation of Rac1 can either alleviate or exacerbate neurodegenerative disease conditions. The data from this review show two studies where PBM activated Rac1 (Song et al. 2012; Meng et al. 2013), but neither of the studies reported any pro-inflammatory effects nor an increase in ROS generation. A study by Sheng Song and colleagues suggested that ROS generated by PBM could be the activators of Src cascade; however, this was not investigated. The same study reported a decrease in pro-inflammatory cytokines and improved microglial phagocytosis (Song et al. 2012).

Similarly, PKC activation was reported to be responsible for the downregulation of $\mathrm{Bax}$ and upregulation of $\mathrm{Bcl}-\mathrm{Xl}$ in PC-12 cells treated with $A \beta_{25-35}$ (Zhang et al. 2008). From other available research studies, PKC is also an inducer of NOX; it activates the assembly of NOX subunits (Rastogi et al. 2017). The data from this review did not find any activation of NOX by PBM. In fact, PBM decreased the activity of NOX by preventing subunit assembly (Yang et al. 2010).

Available literature reports that ERK1/2 MAPK, PI3K/ Akt, and SIRT1 cascades activate mitochondrial fission proteins like Drp1 and promote fission and fragmentation (Guedes-Dias and Oliveira 2013; Cook et al. 2017; Nagdas and Kashatus 2017). Though PBM activates the above pathways, data from this review demonstrate the preservation of mitochondrial fusion and a decrease in fission (Lu et al. 2017). It appears from these instances that when PBM activates a certain protein or pathway, it brings about beneficial changes without activating any other harmful effects of the pathways.

PBM also showed pathology-dependent effects. A study reported that PBM decreased p-Akt and p-HSP27 in a diabetic retinopathy model (Tang et al. 2013) while other studies reported an increase in p-Akt, HSP27, and p-HSP27 in activated microglia and Alzheimer's disease models (Zhang et al. 2012; Liang et al. 2012; Grillo et al. 2013). While activation of Akt has been beneficial in Alzheimer's disease (Liang et al. 2012; Zhang et al. 2012; Chen et al. 2016), it is quite the opposite in diabetic retinopathy where PI3K/ $\mathrm{Akt} / \mathrm{mTOR}$ activation does more harm than good (Jacot and Sherris 2011). This observation suggests that PBM's effects would not be the same in different disease conditions.

Singularly targeting a particular signaling cascade is bound to fail, as seen with most pharmacological drugs for neurodegenerative diseases so far, since each pathway intersects with others to bring about a collective outcome. Suppressing or enhancing any one part of the complicated program can very often cause a whole different outcome. The $\mathrm{p} 38, \mathrm{PI} 3 \mathrm{~K} / \mathrm{Akt} / \mathrm{GSK} 3 \beta$, and SIRT1 pathways are already under scrutiny as potential targets for pharmacological interventions against neurodegeneration. The efficacy of such compounds in humans is yet to be established. GSK3 $\beta$ inhibitor did not show much promise in the phase 2 trials while resveratrol, a SIRT1 activator shows some beneficial results (Munoz and Ammit 2010; Donmez and Outeiro 2013; Zhang et al. 2016; Sawda et al. 2017). Extensive clinical trials are required to judge whether they can succeed. Other than symptomatic treatments, most drugs aimed at slowing disease progression fail in human studies even though they showed promise in animal models (Kiaei 2013). The above-mentioned Rac 1 and PGC- $1 \alpha$ could be targets for pharmacological intervention, given the role of Rac 1 in axonal survival (D'Ambrosi et al. 2014), and the importance of PGC- $1 \alpha$ in mitochondrial biogenesis and suppression of $A \beta$ peptide production (Katsouri et al. 2011; Wang et al. 2013; Zhang et al. 2020). PGC-1 $\alpha$ is also found to be reduced in Alzheimer's disease brains (Qin et al. 2009), and its overexpression as a treatment modality seems to offer some benefit but has also been reported to worsen $A \beta$ and tau deposition and cause dopamine depletion (Clark et al. 2012; Dumont et al. 2014; Katsouri et al. 2016). Targeting the neurotrophic factors like BDNF and GDNF is also being tested for altering disease progression; however, their inability to cross the blood-brain barrier stands as a major ramification (Pilakka-Kanthikeel et al. 2013; Sathiya et al. 2013; d'Anglemont de Tassigny et al. 2015).

From the studies included in this review, it can be observed that PBM affects several intersecting pathways in a disease-dependent manner and nudges the molecular responses of cells in neurodegenerative diseases in the right direction (Fig. 4).

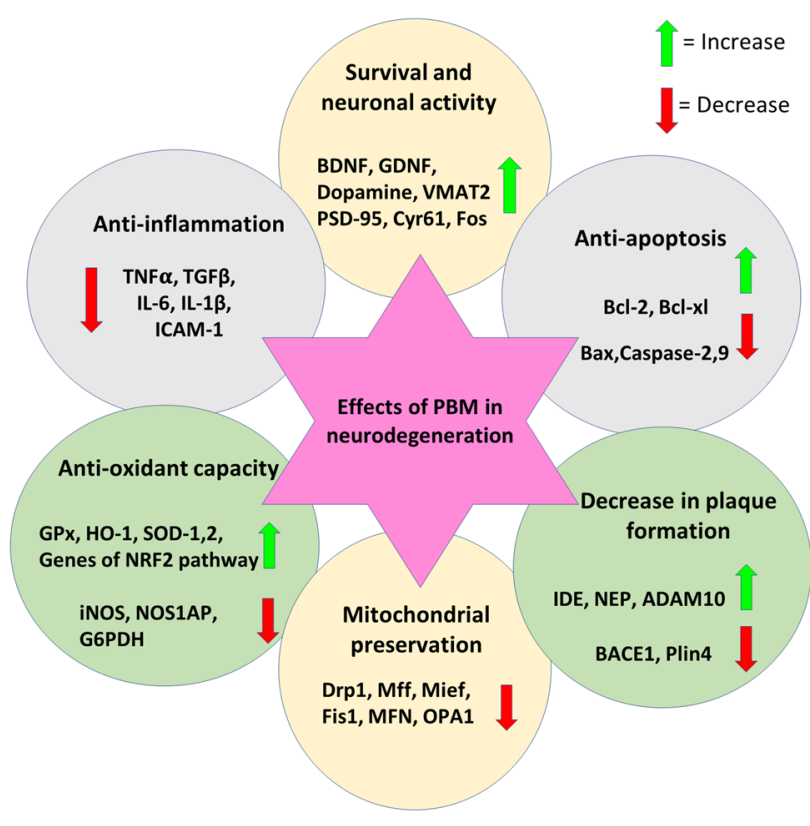

Fig. 4 Overall effects of PBM on genes and proteins playing different roles in neurodegeneration 


\section{Conclusion}

In the present review, we have attempted to extensively highlight some of the significant molecular mechanisms by which photobiomodulation therapy is beneficial against neurodegenerative diseases. PBM modulates several pathways that are essential for stress response and neuronal survival. It improves neuronal survival and activity, attenuates inflammation, enhances the antioxidant capacity, and preserves mitochondrial homeostasis, thereby improving the neurons' resilience and adaptability to cope with cellular insults during neurodegenerative disease progression. The review attempts to summarize the molecular aspects associated with PBM therapy, which could help researchers to better understand the neuronal conditions. The study report indicates that the application of photobiomodulation can be a promising tool for translation to therapeutic intervention, one that can alter the progression of neurodegenerative diseases.

Acknowledgments The authors thank Manipal Academy of Higher Education (MAHE), Manipal, India, and TIFAC-CORE, DST, Govt. of India, for creating the necessary infrastructure and facilities at Manipal School of Life Sciences (MSLS), Manipal, that was used in the present study. Authors would also like to thank Dr. K. Satyamoorthy, Director, Manipal School of Life Sciences, MAHE, Manipal, for his encouragement and support. One of the authors, CRR would like to thank MAHE for providing financial support under Dr. TMA Pai Structured Phd Scheme and Indian Council of Medical Research (ICMR), Goverment of India, for providing Senior Research Fellowship (Sanction No-5/3/8/ITR-F/2018-ITR).

Author contributions KKM had the idea for the article and guided the study; MB and CRR performed the literature search and analysis, wrote the paper, and designed the figures. The final draft was critically revised by KKM.

Funding Open access funding provided by Manipal Academy of Higher Education, Manipal.

\section{Compliance with Ethical Standards}

Conflict of interest Authors declare that they have no conflict of interest.

Open Access This article is licensed under a Creative Commons Attribution 4.0 International License, which permits use, sharing, adaptation, distribution and reproduction in any medium or format, as long as you give appropriate credit to the original author(s) and the source, provide a link to the Creative Commons licence, and indicate if changes were made. The images or other third party material in this article are included in the article's Creative Commons licence, unless indicated otherwise in a credit line to the material. If material is not included in the article's Creative Commons licence and your intended use is not permitted by statutory regulation or exceeds the permitted use, you will need to obtain permission directly from the copyright holder. To view a copy of this licence, visit http://creativecommons.org/licenses/by/4.0/.

\section{References}

Bachstetter AD, Van Eldik LJ (2010) The p38 MAP kinase family as regulators of proinflammatory cytokine production in degenerative diseases of the CNS. Aging Dis 1:199-211

Baird L, Dinkova-Kostova AT (2011) The cytoprotective role of the Keap1-Nrf2 pathway. Arch Toxicol 85:241-272. https://doi. org/10.1007/s00204-011-0674-5

Banerjee A, Khemka VK, Ganguly A et al (2015) Vitamin D and Alzheimer's disease: neurocognition to therapeutics. Int J Alzheimers Dis 2015:1-11. https://doi.org/10.1155/2015/192747

Bertini E, Oka T, Sudol M et al (2009) YAP: at the crossroad between transformation and tumor suppression. Cell Cycle 8:49-57. https ://doi.org/10.4161/cc.8.1.7259

Beurel E, Jope RS (2006) The paradoxical pro- and anti-apoptotic actions of GSK3 in the intrinsic and extrinsic apoptosis signaling pathways. Prog Neurobiol 79:173-189. https://doi.org/10.1016/j. pneurobio.2006.07.006

Binder DK, Scharfman HE (2004) Brain-derived neurotropic factor. Growth Factors 22:123-131. https://doi.org/10.1080/08977 190410001723308

Cai B, Chang SH, Becker EBE et al (2006) p38 MAP kinase mediates apoptosis through phosphorylation of Bim EL at Ser-65. J Biol Chem 281:25215-25222. https://doi.org/10.1074/jbc.M5126 27200

Cerella C, Diederich M, Ghibelli L (2010) The dual role of calcium as messenger and stressor in cell damage, death, and survival. Int J Cell Biol 2010:1-14. https://doi.org/10.1155/2010/546163

Chen XQ, Mobley WC (2019) Alzheimer disease pathogenesis: insights from molecular and cellular biology studies of oligomeric $\mathrm{A} \beta$ and tau species. Front Neurosci 13:659. https://doi. org/10.3389/fnins.2019.00659

Chen Z, Zhong C (2014) Oxidative stress in Alzheimer's disease. Neurosci Bull 30:271-281. https://doi.org/10.1007/s1226 4-013-1423-y

Chen AC, Arany PR, Huang YY et al (2011) Low-level laser therapy activates NF-kB via generation of reactive oxygen species in mouse embryonic fibroblasts. PLoS One 6:e22453. https://doi. org/10.1371/journal.pone.0022453

Chen SD, Zhang B, Wang Y et al (2016) Neuroprotective effects of salidroside through PI3K/Akt pathway activation in Alzheimer's disease models. Drug Des Devel Ther 1335. https://doi. org/10.2147/DDDT.S99958

Cheng Y, Du Y, Liu H et al (2018) Photobiomodulation inhibits longterm structural and functional lesions of diabetic retinopathy. Diabetes 67:291-298. https://doi.org/10.2337/db17-0803

Chinta SJ, Mallajosyula JK, Rane A, Andersen JK (2010) Mitochondrial alpha-synuclein accumulation impairs complex I function in dopaminergic neurons and results in increased mitophagy in vivo. Neurosci Lett 486:235-239. https://doi.org/10.1016/j. neulet.2010.09.061

Cho GM, Lee SY, Park JH et al (2018) Photobiomodulation using a low-level light-emitting diode improves cognitive dysfunction in the 5XFAD mouse model of Alzheimer's disease. J Gerontol Ser A. https://doi.org/10.1093/gerona/gly240

Chung L (2015) A brief introduction to the transduction of neural activity into Fos signal. Dev Reprod 19:61-67. https://doi. org/10.12717/DR.2015.19.2.061

Clark J, Silvaggi JM, Kiselak T et al (2012) Pgc-1 $\alpha$ overexpression downregulates Pitx 3 and increases susceptibility to MPTP toxicity associated with decreased Bdnf. PLoS One 7:e48925. https:// doi.org/10.1371/journal.pone.0048925

Cook SJ, Stuart K, Gilley R, Sale MJ (2017) Control of cell death and mitochondrial fission by ERK1/2 MAP kinase signalling. FEBS J 284:4177-4195. https://doi.org/10.1111/febs. 14122 
D’Ambrosi N, Rossi S, Gerbino V, Cozzolino M (2014) Rac1 at the crossroad of actin dynamics and neuroinflammation in Amyotrophic Lateral Sclerosis. Front Cell Neurosci 8:279. https://doi. org/10.3389/fncel.2014.00279

d'Anglemont de Tassigny X, Pascual A, López-Barneo J (2015) GDNFbased therapies, GDNF-producing interneurons, and trophic support of the dopaminergic nigrostriatal pathway. Implications for Parkinson's disease. Front Neuroanat 9:10. https://doi. org/10.3389/fnana.2015.00010

De Taboada L, Yu J, El-Amouri S et al (2011) Transcranial laser therapy attenuates amyloid- $\beta$ peptide neuropathology in amyloid- $\beta$ protein precursor transgenic mice. J Alzheimers Dis 23:521-535. https://doi.org/10.3233/JAD-2010-100894

De Zutter GS, Davis RJ (2001) Pro-apoptotic gene expression mediated by the p38 mitogen-activated protein kinase signal transduction pathway. Proc Natl Acad Sci 98:6168-6173. https://doi. org/10.1073/pnas.111027698

Deguine J, Barton GM (2014) MyD88: a central player in innate immune signaling. F1000Prime Rep 6. https://doi.org/10.12703 /P6-97

Deng X, Ruvolo P, Carr B, May WS (2000) Survival function of ERK1/2 as IL-3-activated, staurosporine-resistant Bcl2 kinases. Proc Natl Acad Sci 97:1578-1583. https://doi.org/10.1073/ pnas.97.4.1578

Dong X, Wang Y, Qin Z (2009) Molecular mechanisms of excitotoxicity and their relevance to pathogenesis of neurodegenerative diseases. Acta Pharmacol Sin 30:379-387. https://doi.org/10.1038/ aps. 2009.24

Donmez G, Outeiro TF (2013) SIRT1 and SIRT2: emerging targets in neurodegeneration. EMBO Mol Med 5:344-352. https://doi. org/10.1002/emmm.201302451

Dumaz N, Marais R (2005) Integrating signals between cAMP and the RAS/RAF/MEK/ERK signalling pathways. Based on the anniversary prize of the Gesellschaft für Biochemie und Molekularbiologie lecture delivered on 5 July 2003 at the Special FEBS Meeting in Brussels. FEBS J 272:3491-3504. https://doi.org/10 $.1111 / \mathrm{j} .1742-4658.2005 .04763 . \mathrm{x}$

Dumont M, Stack C, Elipenahli C et al (2014) PGC-1 $\alpha$ : overexpression exacerbates $\beta$-amyloid and tau deposition in a transgenic mouse model of Alzheimer's disease. FASEB J 28:1745-1755. https:// doi.org/10.1096/fj.13-236331

Eiden LE, Weihe E (2011) VMAT2: a dynamic regulator of brain monoaminergic neuronal function interacting with drugs of abuse. Ann N Y Acad Sci 1216:86-98. https://doi.org/10.111 1/j.1749-6632.2010.05906.x

El Massri N, Lemgruber AP, Rowe IJ et al (2017) Photobiomodulation-induced changes in a monkey model of Parkinson's disease: changes in tyrosine hydroxylase cells and GDNF expression in the striatum. Exp Brain Res 235:1861-1874. https://doi. org/10.1007/s00221-017-4937-0

Endres K, Deller T (2017) Regulation of alpha-secretase ADAM10 in vitro and in vivo: genetic, epigenetic, and protein-based mechanisms. Front Mol Neurosci 10. https://doi.org/10.3389/fnmol .2017 .00056

Estrada Sánchez AM, Mejía TJ, Massieu L (2008) Excitotoxic neuronal death and the pathogenesis of Huntington's disease. Arch Med Res 39:265-276. https://doi.org/10.1016/j.arcmed.2007.11.011

Federico A, Cardaioli E, Da Pozzo P et al (2012) Mitochondria, oxidative stress and neurodegeneration. J Neurol Sci 322:254-262. https://doi.org/10.1016/j.jns.2012.05.030

Ganeshan V, Skladnev NV, Kim JY et al (2019) Pre-conditioning with remote photobiomodulation modulates the brain transcriptome and protects against MPTP insult in mice. Neuroscience 400:8597. https://doi.org/10.1016/j.neuroscience.2018.12.050
Gao J, Wang L, Liu J et al (2017) Abnormalities of mitochondrial dynamics in neurodegenerative diseases. Antioxidants 6:25. https ://doi.org/10.3390/antiox6020025

Gerhart-Hines Z, Dominy JE, Blättler SM et al (2011) The cAMP/PKA pathway rapidly activates SIRT1 to promote fatty acid oxidation independently of changes in NAD+. Mol Cell 44:851-863. https ://doi.org/10.1016/j.molcel.2011.12.005

Gezen-Ak D, Dursun E, Yilmazer S (2014) The effect of vitamin D treatment on nerve growth factor (NGF) release from hippocampal neurons. Noro Psikiyatr Ars 51:157-162. https://doi. org/10.4274/npa.y7076

Goldsmith ZG, Dhanasekaran DN (2007) G protein regulation of MAPK networks. Oncogene 26:3122-3142. https://doi. org/10.4103/1673-5374.262573

Gordon LC, Johnstone DM (2019) Remote photobiomodulation: an emerging strategy for neuroprotection. Neural Regen Res 14:2086-2087. https://doi.org/10.4103/1673-5374.262573

Grillo SL, Duggett NA, Ennaceur A, Chazot PL (2013) Non-invasive infra-red therapy $(1072 \mathrm{~nm})$ reduces $\beta$-amyloid protein levels in the brain of an Alzheimer's disease mouse model, TASTPM. J Photochem Photobiol B Biol 123:13-22. https:// doi.org/10.1016/j.jphotobiol.2013.02.015

Gu X, Liu L, Shen Q, Xing D (2017) Photoactivation of ERK/CREB/ VMAT2 pathway attenuates MPP+-induced neuronal injury in a cellular model of Parkinson's disease. Cell Signal 37:103114. https://doi.org/10.1016/j.cellsig.2017.06.007

Guedes-Dias P, Oliveira JMA (2013) Lysine deacetylases and mitochondrial dynamics in neurodegeneration. Biochim Biophys Acta Mol basis Dis 1832:1345-1359. https://doi.org/10.1016/j. bbadis.2013.04.005

Hamblin MR (2016) Shining light on the head: Photobiomodulation for brain disorders. BBA Clin 6:113-124. https://doi. org/10.1016/j.bbacli.2016.09.002

Hashikawa N, Utaka Y, Ogawa T et al (2017) HSP105 prevents depression-like behavior by increasing hippocampal brain-derived neurotrophic factor levels in mice. Sci Adv 3:e1603014. https://doi.org/10.1126/sciadv.1603014

Havasi A, Li Z, Wang Z et al (2008) Hsp27 inhibits Bax activation and apoptosis via a phosphatidylinositol 3-kinase-dependent mechanism. J Biol Chem 283:12305-12313. https://doi. org/10.1074/jbc.M801291200

Heo JC, Park JA, Kim DK, Lee JH (2019) Photobiomodulation $(660 \mathrm{~nm})$ therapy reduces oxidative stress and induces BDNF expression in the hippocampus. Sci Rep 9:10114. https://doi. org/10.1038/s41598-019-46490-4

Herbst A, Jurinovic V, Krebs S et al (2014) Comprehensive analysis of $\beta$-catenin target genes in colorectal carcinoma cell lines with deregulated Wnt/ $\beta$-catenin signaling. BMC Genomics 15:74. https://doi.org/10.1186/1471-2164-15-74

Hernandez-Zimbron LF, Luna-Muñoz J, Mena R et al (2012) Amyloid- $\beta$ peptide binds to cytochrome $\mathrm{C}$ oxidase subunit 1. PLoS One 7:e42344. https://doi.org/10.1371/journ al.pone. 0042344

Hoesel B, Schmid JA (2013) The complexity of NF- $\kappa$ B signaling in inflammation and cancer. Mol Cancer 12:86. https://doi. org/10.1186/1476-4598-12-86

Huang YY, Nagata K, Tedford CE et al (2013) Low-level laser therapy (LLLT) reduces oxidative stress in primary cortical neurons in vitro. J Biophotonics 6:829-838. https://doi. org/10.1002/jbio.201200157

Huang YY, Nagata K, Tedford CE, Hamblin MR (2014) Low-level laser therapy $(810 \mathrm{~nm})$ protects primary cortical neurons against excitotoxicity in vitro. J Biophotonics 7:656-664. https ://doi.org/10.1002/jbio.201300125

Jacot JL, Sherris D (2011) Potential therapeutic roles for inhibition of the PI3K/Akt/mTOR pathway in the pathophysiology 
of diabetic retinopathy. J Ophthalmol 2011:1-19. https://doi. org/10.1155/2011/589813

Jafari M, Ghadami E, Dadkhah T, Akhavan-Niaki H (2019) PI3k/ AKT signaling pathway: erythropoiesis and beyond. J Cell Physiol 234:2373-2385. https://doi.org/10.1002/jcp.27262

Johnstone DM, Moro C, Stone J et al (2016) Turning on lights to stop neurodegeneration: the potential of near infrared light therapy in Alzheimer's and Parkinson's disease. Front Neurosci:9. https ://doi.org/10.3389/fnins.2015.00500

Katsouri L, Parr C, Bogdanovic N et al (2011) PPAR $\gamma$ co-activator- $1 \alpha$ $(\mathrm{PGC}-1 \alpha)$ reduces amyloid- $\beta$ generation through a PPAR $\gamma-$ dependent mechanism. J Alzheimers Dis 25:151-162. https:// doi.org/10.3233/JAD-2011-101356

Katsouri L, Lim YM, Blondrath K et al (2016) PPAR $\gamma$-coactivator- $1 \alpha$ gene transfer reduces neuronal loss and amyloid- $\beta$ generation by reducing $\beta$-secretase in an Alzheimer's disease model. Proc Natl Acad Sci 113:12292-12297. https://doi.org/10.1073/ pnas. 1606171113

Keith D (2008) Excitation control: balancing PSD-95 function at the synapse. Front Mol Neurosci 1. https://doi.org/10.3389/neuro .02 .004 .2008

Kiaei M (2013) New hopes and challenges for treatment of neurodegenerative disorders: great opportunities for young neuroscientists. Basic Clin Neurosci 4:3-4

Kumar RN, George BP, Chandran R et al (2019) The influence of light on reactive oxygen species and NF- $\mathrm{KB}$ in disease progression. Antioxidants 8:640. https://doi.org/10.3390/antiox8120640

Kummer JL, Rao PK, Heidenreich KA (1997) Apoptosis induced by withdrawal of trophic factors is mediated by p38 mitogen-activated protein kinase. J Biol Chem 272:20490-20494. https://doi. org/10.1074/jbc.272.33.20490

Lee JH, Chiang MH, Chen PH et al (2018) Anti-inflammatory effects of low-level laser therapy on human periodontal ligament cells: in vitro study. Lasers Med Sci 33:469-477. https://doi. org/10.1007/s10103-017-2376-6

Liang J, Liu L, Xing D (2012) Photobiomodulation by low-power laser irradiation attenuates $\mathrm{A} \beta$-induced cell apoptosis through the Akt/ GSK3 $\beta / \beta$-catenin pathway. Free Radic Biol Med 53:1459-1467. https://doi.org/10.1016/j.freeradbiomed.2012.08.003

Liu T, Zhang L, Joo D, Sun S-C (2017) NF-кB signaling in inflammation. Signal Transduct Target Ther 2:17023. https://doi. org/10.1038/sigtrans.2017.23

Lu Y, Wang R, Dong Y et al (2017) Low-level laser therapy for beta amyloid toxicity in rat hippocampus. Neurobiol Aging 49:165182. https://doi.org/10.1016/j.neurobiolaging.2016.10.003

Maiti P, Manna J, Dunbar GL (2017) Current understanding of the molecular mechanisms in Parkinson's disease: targets for potential treatments. Transl Neurodegener 6:28. https://doi. org/10.1186/s40035-017-0099-Z

Meng C, He Z, Xing D (2013) Low-level laser therapy rescues dendrite atrophy via upregulating BDNF expression: implications for Alzheimer's disease. J Neurosci 33:13505-13517. https://doi. org/10.1523/JNEUROSCI.0918-13.2013

Meng Q, Li BX, Xiao X (2018) Toward developing chemical modulators of Hsp60 as potential therapeutics. Front Mol Biosci 5. https ://doi.org/10.3389/fmolb.2018.00035

Moccia N, Shekha et al (2019) Endothelial Ca2+ signaling, angiogenesis and vasculogenesis: just what it takes to make a blood vessel. Int J Mol Sci 20:3962. https://doi.org/10.3390/ijms20163962

Muili KA, Gopalakrishnan S, Eells JT, Lyons J-A (2013) Photobiomodulation induced by $670 \mathrm{~nm}$ light ameliorates MOG35-55 induced EAE in female C57BL/6 mice: a role for remediation of nitrosative stress. PLoS One 8:e67358. https://doi.org/10.1371/ journal.pone. 0067358
Munoz L, Ammit AJ (2010) Targeting p38 MAPK pathway for the treatment of Alzheimer's disease. Neuropharmacology 58:561568. https://doi.org/10.1016/j.neuropharm.2009.11.010

Nagdas S, Kashatus DF (2017) The interplay between oncogenic signaling networks and mitochondrial dynamics. Antioxidants (Basel, Switzerland) 6:33. https://doi.org/10.3390/antiox6020033

Oron A, Oron U (2016) Low-level laser therapy to the bone marrow ameliorates neurodegenerative disease progression in a mouse model of Alzheimer's disease: a minireview. Photomed Laser Surg 34:627-630. https://doi.org/10.1089/pho.2015.4072

Oueslati A, Lovisa B, Perrin J et al (2015) Photobiomodulation suppresses alpha-synuclein-induced toxicity in an AAV-based rat genetic model of Parkinson's disease. PLoS One 10:e0140880. https://doi.org/10.1371/journal.pone.0140880

Pagani L, Eckert A (2011) Amyloid-beta interaction with mitochondria. Int J Alzheimers Dis 2011:1-12. https://doi. org/10.4061/2011/925050

Pilakka-Kanthikeel S, Atluri VSR, Sagar V et al (2013) Targeted brain derived neurotropic factors (BDNF) delivery across the blood-brain barrier for neuro-protection using magnetic nano carriers: an in-vitro study. PLoS One 8:e62241. https://doi. org/10.1371/journal.pone.0062241

Pinho CM, Teixeira PF, Glaser E (2014) Mitochondrial import and degradation of amyloid- $\$ \beta$ peptide. Biochim Biophys Acta Bioenerg 1837:1069-1074. https://doi.org/10.1016/j.bbabi o.2014.02.007

Pozo Devoto VM, Falzone TL (2017) Mitochondrial dynamics in Parkinson's disease: a role for $\$ \alpha \$$-synuclein? Dis Model Mech 10:1075-1087. https://doi.org/10.1242/dmm.026294

Purushothuman S, Johnstone DM, Nandasena C et al (2014) Photobiomodulation with near infrared light mitigates Alzheimer's disease-related pathology in cerebral cortex - evidence from two transgenic mouse models. Alzheimers Res Ther 6:2. https ://doi.org/10.1186/alzrt232

Qin W, Haroutunian V, Katsel P et al (2009) PGC-1 $\alpha$ expression decreases in the Alzheimer disease brain as a function of dementia. Arch Neurol 66. https://doi.org/10.1001/archneurol .2008 .588

Rastogi R, Geng X, Li F, Ding Y (2017) NOX activation by subunit interaction and underlying mechanisms in disease. Front Cell Neurosci 10. https://doi.org/10.3389/fncel.2016.00301

Raynes R, Brunquell J, Westerheide SD (2013) Stress inducibility of SIRT1 and its role in cytoprotection and cancer. Genes Cancer 4:172-182. https://doi.org/10.1177/1947601913484497

Rizzi CF, Mauriz JL, Freitas Corrêa DS et al (2006) Effects of lowlevel laser therapy (LLLT) on the nuclear factor (NF)- $\kappa B$ signaling pathway in traumatized muscle. Lasers Surg Med 38:704-713. https://doi.org/10.1002/lsm.20371

Salehpour F, Mahmoudi J, Kamari F et al (2018) Brain Photobiomodulation therapy: a narrative review. Mol Neurobiol 55:6601-6636. https://doi.org/10.1007/s12035-017-0852-4

San Miguel M, Martin KL, Stone J, Johnstone DM (2019) Photobiomodulation mitigates cerebrovascular leakage induced by the parkinsonian neurotoxin MPTP. Biomolecules 9(10):564. https://doi.org/10.3390/biom9100564

Sanabria-Castro A, Alvarado-Echeverría I, Monge-Bonilla C (2017) Molecular pathogenesis of Alzheimer's disease: an update. Ann Neurosci 24:46-54. https://doi.org/10.1159/000464422

Sathiya S, Ranju V, Kalaivani P et al (2013) Telmisartan attenuates MPTP induced dopaminergic degeneration and motor dysfunction through regulation of $\alpha$-synuclein and neurotrophic factors (BDNF and GDNF) expression in C57BL/6J mice. Neuropharmacology 73:98-110. https://doi.org/10.1016/j.neuropharm .2013.05.025 
Sawda C, Moussa C, Turner RS (2017) Resveratrol for Alzheimer's disease. Ann N Y Acad Sci 1403:142-149. https://doi. org/10.1111/nyas.13431

Song S, Zhou F, Chen WR (2012) Low-level laser therapy regulates microglial function through Src-mediated signaling pathways: implications for neurodegenerative diseases. J Neuroinflammation 9:707. https://doi.org/10.1186/1742-2094-9-219

Stetler RA, Gao Y, Signore AP et al (2009) HSP27: mechanisms of cellular protection against neuronal injury. Curr Mol Med 9:863-872. https://doi.org/10.2174/156652409789105561

Sun GY, Chuang DY, Zong Y et al (2014) Role of cytosolic phospholipase A2 in oxidative and inflammatory signaling pathways in different cell types in the central nervous system. Mol Neurobiol 50:6-14. https://doi.org/10.1007/s12035-014-8662-4

Tang J, Du Y, Lee CA et al (2013) Low-intensity far-red light inhibits early lesions that contribute to diabetic retinopathy: in vivo and in vitro. Invest Opthalmol Vis Sci 54:3681. https://doi. org/10.1167/iovs.12-11018

Turturici G, Sconzo G, Geraci F (2011) Hsp70 and its molecular role in nervous system diseases. Biochem Res Int 2011:618127. https://doi.org/10.1155/2011/618127

Vaarmann A, Kovac S, Holmström KM et al (2013) Dopamine protects neurons against glutamate-induced excitotoxicity. Cell Death Dis 4:e455. https://doi.org/10.1038/cddis.2012.194

Wang R, Li JJ, Diao S et al (2013) Metabolic stress modulates Alzheimer's $\beta$-secretase gene transcription via SIRT1-PPAR $\gamma$-PGC-1 in neurons. Cell Metab 17:685-694. https://doi.org/10.1016/j. cmet.2013.03.016

Wang R, Dong Y, Lu Y et al (2019) Photobiomodulation for global cerebral ischemia: targeting mitochondrial dynamics and functions. Mol Neurobiol 56:1852-1869. https://doi.org/10.1007/ s12035-018-1191-9

Wei L, Mousawi F, Li D et al (2019) Adenosine triphosphate release and $\mathrm{P} 2$ receptor signaling in Piezo1 channel-dependent mechanoregulation. Front Pharmacol 10. https://doi.org/10.3389/fphar .2019 .01304

Weissmiller AM, Wu C (2012) Current advances in using neurotrophic factors to treat neurodegenerative disorders. Transl Neurodegener 1:14. https://doi.org/10.1186/2047-9158-1-14

Wong-Riley MTT, Liang HL, Eells JT et al (2005) Photobiomodulation directly benefits primary neurons functionally inactivated by toxins. J Biol Chem 280:4761-4771. https://doi.org/10.1074/ jbc.M409650200

Xu J, Jackson CW, Khoury N et al (2018) Brain SIRT1 mediates metabolic homeostasis and neuroprotection. Front Endocrinol (Lausanne) 9. https://doi.org/10.3389/fendo.2018.00702
Yang Y, Zhu X, Chen Y et al (2007) p38 and JNK MAPK, but not ERK1/2 MAPK, play important role in colchicine-induced cortical neurons apoptosis. Eur J Pharmacol 576:26-33. https://doi. org/10.1016/j.ejphar.2007.07.067

Yang X, Askarova S, Sheng W et al (2010) Low energy laser light $(632.8 \mathrm{~nm})$ suppresses amyloid- $\beta$ peptide-induced oxidative and inflammatory responses in astrocytes. Neuroscience 171:859868. https://doi.org/10.1016/j.neuroscience.2010.09.025

Zhang L, Xing D, Zhu D, Chen Q (2008) Low-power laser irradiation inhibiting Abeta 25-35-induced PC12 cell apoptosis via PKC activation. Cell Physiol Biochem 22:215-222. https://doi. org/10.1159/000149799

Zhang H, Wu S, Xing D (2012) Inhibition of Aß25-35-induced cell apoptosis by low-power-laser-irradiation (LPLI) through promoting Akt-dependent YAP cytoplasmic translocation. Cell Signal 24:224-232. https://doi.org/10.1016/j.cellsig.2011.09.004

Zhang S, Zhao Y, Xu M et al (2013) FoxO3a modulates hypoxia stress induced oxidative stress and apoptosis in cardiac microvascular endothelial cells. PLoS One 8:e80342. https://doi.org/10.1371/ journal.pone.0080342

Zhang J, Wang X, Vikash V et al (2016) ROS and ROS-mediated cellular signaling. Oxidative Med Cell Longev 2016:1-18. https:// doi.org/10.1155/2016/4350965

Zhang Z, Shen Q, Wu X et al (2020) Activation of PKA/SIRT1 signaling pathway by photobiomodulation therapy reduces $\mathrm{A} \beta$ levels in Alzheimer's disease models. Aging Cell 19(1):e13054sana. https://doi.org/10.1111/acel.13054

Zheng WH, Bastianetto S, Mennicken F et al (2002) Amyloid beta peptide induces tau phosphorylation and loss of cholinergic neurons in rat primary septal cultures. Neuroscience 115:201-211. https ://doi.org/10.1016/s0306-4522(02)00404-9

Zheng F, Zhou X, Moon C, Wang H (2012) Regulation of brain-derived neurotrophic factor expression in neurons. Int J Physiol Pathophysiol Pharmacol 4:188-200

Zhou Y, Wang S, Li Y et al (2018) SIRT1/PGC-1 $\alpha$ signaling promotes mitochondrial functional recovery and reduces apoptosis after intracerebral hemorrhage in rats. Front Mol Neurosci 10. https ://doi.org/10.3389/fnmol.2017.00443

Publisher's Note Springer Nature remains neutral with regard to jurisdictional claims in published maps and institutional affiliations 